\title{
Caracterización de contagiados por COVID-19 en el Departamento del Atlántico
}

\section{Characterization of infected by COVID-19 in the Department of Atlántico}

DOI: http://doi.org/10.17981/bilo.2.1.2020.5

Artículo de Investigación Científica. Fecha de Recepción: 30/05/2020. Fecha de Aceptación: 13/06/2020

\author{
Carolina Bustamante Meléndez \\ Universidad de la Costa CUC. Barranquilla, Colombia \\ cbustama4@cuc.edu.co \\ Diego Amaris Rueda \\ Universidad de la Costa CUC. Barranquilla, Colombia \\ damaris@cuc.edu.co \\ Saadath Mora Piña \\ Universidad de la Costa CUC. Barranquilla, Colombia \\ Smora2@cuc.edu.co \\ Alexander Troncoso-Palacio \\ Universidad de la Costa CUC. Barranquilla. Colombia \\ atroncos1@cuc.edu.co
}

Para citar este artículo:

C. Bustamante Meléndez, D. Amaris Rueda, S. Mora Piña, A. Troncoso-Palacio, “Caracterización de contagiados por covid-19 en el Departamento del Atlántico", BILO, vol. 2, no. 1, 2020. DOI: http://doi.org/10.17981/bilo.2.1.2020.5

\begin{abstract}
Resumen
Cuando se habla de COVID-19 departamento del Atlántico, el déficit estructural es evidente, tanto económica como social y culturalmente. Es una prueba para el sistema de salud, pero también mide la capacidad de las personas para afrontar cambios, además, se convierte en una batalla incansable para sobrevivir en situaciones austeras. El objetivo de este artículo es determinar el grado de preparación del departamento del Atlántico para enfrentar la pandemia, desde sus habitantes de lo común, hasta las líneas más altas del poder departamental, a través de esta investigación se logró la verificación de que él departamento no está preparado ni siquiera para atender al 1\% de la población; En el evento de que el número de contagiados que requieran atención hospitalaria llegue hasta uno de cada cien habitantes, el sistema de salud colapsaría. En el diagrama de Pareto, se muestra la cantidad de afectados en cada municipio.
\end{abstract}

Palabras clave: COVID-19; Recursos; Municipios; Colapso; Aislamiento. 


\begin{abstract}
When talking about COVID-19 in department of Atlántico, the structural deficit is evident, both economically, socially and culturally. It is a test for health system, but it also measures the ability of people to cope with change, in addition, it becomes a tireless battle to survive in austere situations. The objective of this article is to determine the degree of readiness of the Atlántico department to face the pandemic, from its ordinary inhabitants to the highest lines of the departmental power. Through this investigation, verification was made that the department did not it is not even prepared to serve $1 \%$ of the population; In the event that the number of infected people requiring hospital care reaches up to one in a hundred inhabitants, the health system would collapse. The Pareto diagram shows the number of people affected in each municipality. At end research it is concluded that the Atlántico department does not have sufficient availability to face the pandemic, because its capacity to attend hospitals and clinics is deficient.
\end{abstract}

Key Words: COVID-19; Resources; Municipalities; Collapse; Isolation

\title{
I. INTRODUCCIÓN
}

Desde inicios de la pandemia declarada por la OMS el departamento del Atlántico ha tomado medidas para evitar la propagación de este en todo su territorio, desde la gobernación y las alcaldías de sus 23 municipios se han implementado estrategias como el cierre de fronteras locales, pico y cedula, cuarentena obligatoria, lavado y desinfección en algunos de sus centros comerciales y almacenes de cadena. ¿Pero realmente está preparado el Departamento para enfrentar la pandemia una vez se implemente la llamada cuarentena inteligente planteada por el gobierno Nacional? ¿Está la red hospitalaria y de emergencias equipada técnica y humanamente para enfrentar la crisis? ¿Cuenta el departamento con los recursos destinados a la Salud suficientes para lograr aplanar la curva de la pandemia en tiempo oportuno? Son estas y muchas otras preguntas las que miles de Atlanticenses se hacen a diario, pero todavía no encuentran una respuesta.

\section{ESTUDIO PRIMARIO DE LA LITERATURA}

El departamento del Atlántico hace lo posible para controlar el número de casos de COVID 19 en su territorio, ha diseñado estrategias de prevención y se prepara para un posible contagio masivo [1], pero la verdad es que aún no cuenta con los recursos disponibles para atender como se debe esta pandemia, no cuenta con los equipos suficientes para dar tratamiento a sus habitantes, solo se espera que el número de contagiados empiece a disminuir en los 11 municipios con presencia del virus y que este no llegue a los 13 municipios que aún no tienen presencia del virus. A la fecha solo se está preparado para atender en la red de hospitales y clínicas al $0,16 \%$ de la población de los municipios con casos positivos [2], de ser mayor el porcentaje de personas que requieran atención en centro de salud, se estaría frente a un colapso del sistema de salud departamental. Aunque las cifras presentadas por el Gobierno nacional parecen ser alentadoras comparadas con los otros países que sufren con la pandemia, lo cierto es que cada día aumenta el número de casos y eso hace que cada día se agoten recursos y de no lograrse aplanar la curva, lo realmente cierto es que se vivirá un colapso del sistema de salud y se fraccionara de tal modo la economía que se tardaran años para poder volver a tener una vida como se estaba acostumbrada. Según el último reporte de los datos estadísticos nacionales en Colombia a la fecha hay confirmados 26668 casos de los cuales 6913 se han recuperado y 853 han muerto [6], pero lo cierto es que probablemente hay muchos más casos, casos que no se han descubierto por la incapacidad para realizar los estudios necesarios y por la misma demora del virus para presentar síntomas. Al finalizar se concluye que departamento del Atlántico no cuenta con la disponibilidad suficiente para afrontar la pandemia, debido a que su capacidad para atender en hospitales y clínica es deficiente

\section{METODOLOGIA}

Se utilizó una metodología descriptiva y analítica iniciando con la recolección y tabulación de la información encontrada en los website luego se caracterizó la información la cual queda registrada en los respectivos gráficos y finalmente se concluye la investigación.

\section{DESARROLLO}

De los 25366 casos presentados en el territorio nacional, en el departamento del Atlántico se han encontrado 3277 [3] es decir el 12,91\% del total nacional. Estos casos en el departamento se distribuyen de la siguiente manera Barranquilla 1704 casos, Soledad 964 casos, Puerto Colombia 30 casos, Baranoa 29 casos, Malambo 250casos, Galapa 62 casos, Ponedera 7 caso, Santo tomas 41 casos, Sabana Grande 89 casos, Polonuevo 12 casos. De esta forma puede decirse que 
BILO Vol. 2 no. 1, Enero- Junio de 2020

el virus a alcanzado a 10 de los 23 municipios del departamento [5]. Se analice mejor esta información desde el diagrama de Pareto.

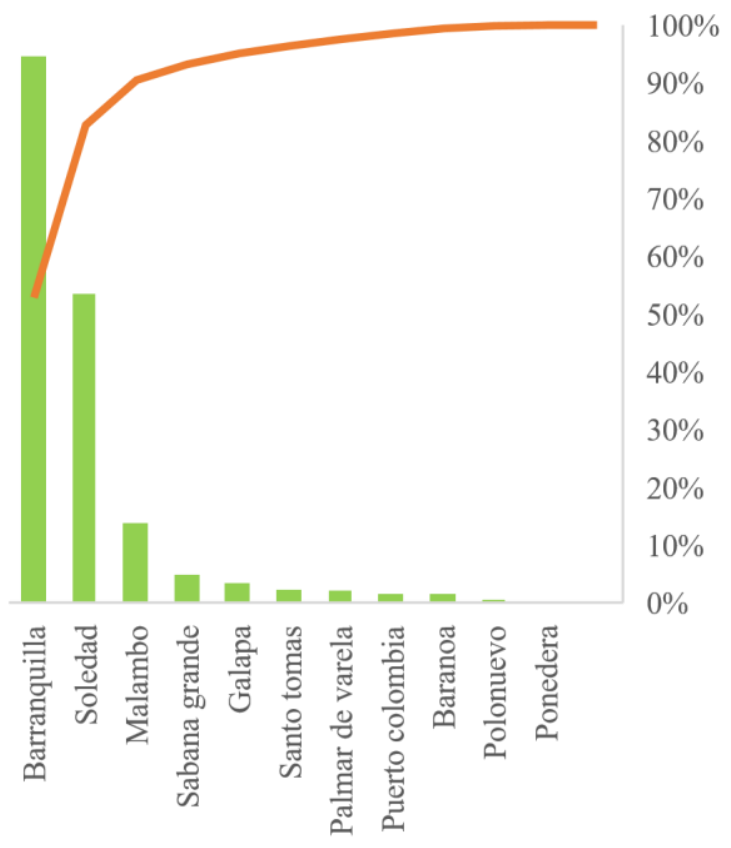

Grafica 1. Casos confirmados COVID 19 por municipios

El diagrama de Pareto muestra que se deben centrar esfuerzos en aquellos municipios que forman el $80 \%$ de los casos, es decir se debe priorizar la atención en Barranquilla y Soledad, aunque se debe aclarar que no se debe bajar la guardia frente a los otros municipios, es más se debe seguir un estricto control en estos 11 municipios ya que los casos han ido aumentando día a día. En una investigación mucho más detallada veamos el comportamiento y los resultados de los casos en los diferentes municipios, describiendo por medio de este grafico de torta podemos observar el porcentaje por genero en el departamento del atlántico donde el 57\% de los contagios son hombres y el $43 \%$ son mujeres.

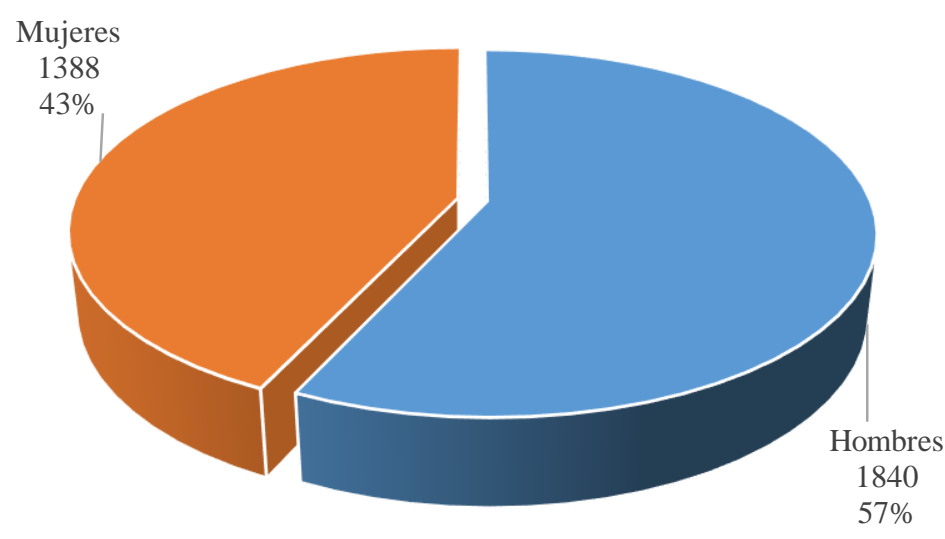

Grafica 2. Gráfico de torta. Numero de contagiados por género.

Existe información que es de suma importancia conocer, aparte de los casos, se debe conocer la capacidad del sistema de salud en estos municipios para enfrentar un posible aumento en el número de pacientes positivos para COVID 19, es decir, la cantidad de camas disponibles en estos municipios para atender la pandemia. 
BILO Vol. 2 no. 1, Enero- Junio de 2020

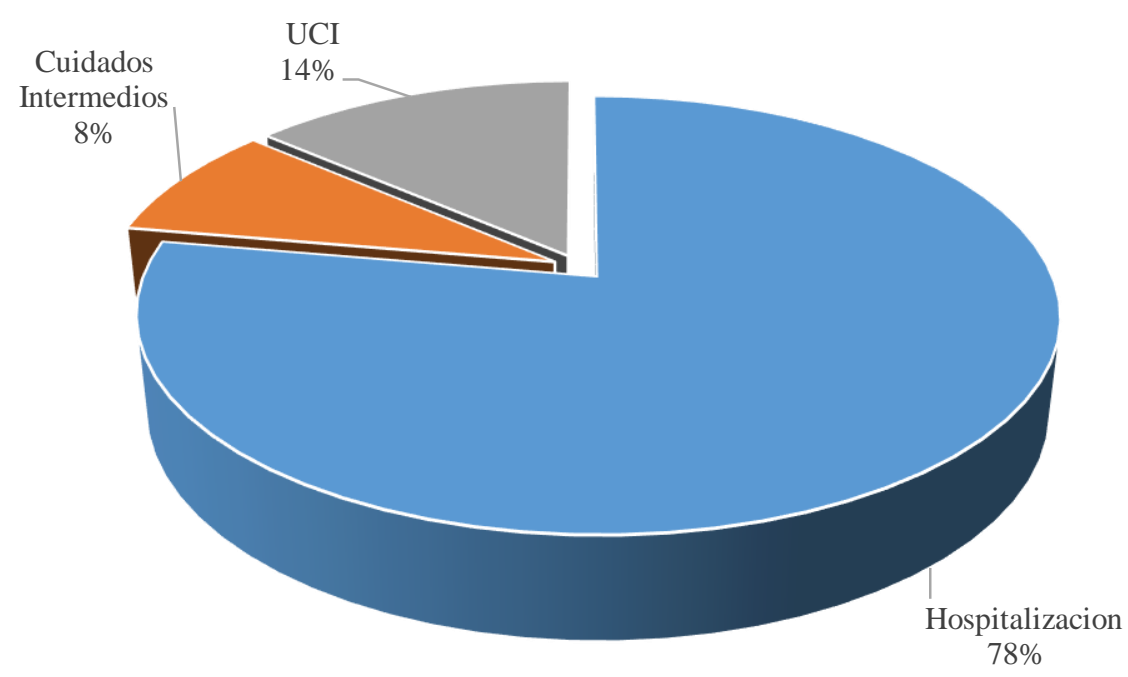

Grafica 3. Camas disponibles en el departamento del Atlántico.

En la tabla 1 se puede observar un panorama más complicado y desalentador, siendo positivos y suponiendo en el mejor de los casos que no se dé ningún contagio en los 13 municipios no sigan aumentando los casos de COVID 19, se puede apreciar que los municipios con presencia del virus no tiene camas suficientes para afrontar la pandemia, solo tiene la capacidad para atender en hospitales y clínicas al 0,16\% de la población total de los 10 municipios, es decir en caso de que se enfermara 1 de cada 100 personas con requerimiento de atención en centro de salud, se colapsaría el sistema y nos enfrentaríamos a una crisis aun mayor, con una eventual conglomeración de pacientes en centros de salud, atendidos por médicos y enfermeros que no cuentan con los equipos de protección adecuados y que están prestos a enfermarse como es el caso de los 4 trabajadores de la salud que dieron positivo al virus en el departamento, y lo peor es que estos hoy llamados "héroes" pero la mayor cantidad del tiempo olvidados por la sociedad y el Estado, no pueden siquiera pedir que se les realice la prueba para descartar ser portadores del virus, tal fue el caso de la médico Alejandra Dulcey Mejía, quien laboró hasta el día 17 de abril en el camino Bosques de María, despedida un día después de pedir que se le realizara la prueba, debido a que en días pasados habían atendido a un paciente que dio positivo para COVID 19 [4].

\begin{tabular}{lr}
\hline Municipio & Confirmados \\
\hline Barranquilla & 1704 \\
Soledad & 964 \\
Puerto Colombia & 30 \\
Baranoa & 29 \\
Malambo & 250 \\
Galapa & 62 \\
Polonuevo & 12 \\
Ponedera & 7 \\
Santo tomas & 41 \\
Sabana grande & 89 \\
Palmar de varela & 40 \\
Total & 3228 \\
\hline
\end{tabular}

Tabla 1. Personas contagiadas con covid-19 en el Atlántico y Barranquilla

\section{CONCLUSION}

Tras una evaluación adecuada de los resultados obtenido a través de la herramienta diagrama de Pareto, gráfico de torta, se puede observar que el departamento del Atlántico no cuenta con la disponibilidad suficiente para afrontar la pandemia ya que su capacidad para atender en hospitales y clínica es deficiente y el sistema de salud se vería colapsado por la cantidad de contagiados por el Covid -19 debido a que su población no ha respetado las medidas de aislamiento establecidas por el gobierno departamental. 
BILO Vol. 2 no. 1, Enero- Junio de 2020

\section{Referencias}

1. Arcgis. (20 de 05 de 2020). www.arcgis.com. Obtenido de www.arcgis.com: https://www.arcgis.com/apps/opsdashboard/index.html\#/8fb083deb0f749919ef8fb98ff0ae1bc

2. Barranquilla, A. d. (22 de 05 de 2020). Alcaldia de Barranquilla. Obtenido de Alcaldia de Barranquilla: https://www.barranquilla.gov.co/salud/coronavirus/decretos-durante-la-emergencia-coronavirus-barranquilla

3. Cero, Z. (22 de 04 de 2020). Zona Cero. Obtenido de Zona Cero: [1] http://zonacero.com/generales/4profesionales-de-la-salud-infectados-por-covid-19-en-barranquilla-y-desvincularon-la-que

4. Colombia, E. (29 de 05 de 2020). Tablero de Control Covid-19. Obtenido de Tablero de Control Covid-19: https://www.arcgis.com/apps/opsdashboard/index.html\#/8fb083deb0f749919ef8fb98ff0ae1bc

5. MC. (30 de 04 de 2020). Lo mas Treding. Obtenido de Lo mas Treding:

https://co.marca.com/claro/trending/2020/04/07/5e8c96d946163ff5058b4660.html

6. MinSalud, [. (29 de 05 de 2020). Sispro. Obtenido de Sispro: https://minsalud.maps.arcgis.com/apps/opsdashboard/index.html\#/1de89936b24449edb77e162d485ed5d9

7. Salud, O. M. (29 de 05 de 2020). Sitio Web Mundial. Obtenido de Sitio Web Mundial: https://www.who.int/es/emergencies/diseases/novel-coronavirus2019?gclid=CjwKCAjwh472BRAGEiwAvHVfGlzE0gm_fQvX_yTZwR1E4Vq5b57Zgusk9neFkHacv9tMDMP3AnIphoCsk4QAvD_BwE 